\title{
CARBON RECYCLING AS AN ENABLER OF A RENEWABLE HYDROGEN ECONOMY
}

\author{
STEFAN PETTERS ${ }^{1}$, DI KLAUS MAUTHNER ${ }^{2} \&$ KALVIN TSE $^{3}$ \\ ${ }^{1}$ guo - Business Development Consult, Austria \\ ${ }^{2}$ KatyushaTec, Vienna [AUT], Austria \\ ${ }^{3}$ Bestrong International Ltd., Hong Kong
}

\begin{abstract}
In a simplified view, nature builds any life matter from just carbon and water, chemically storing the sun's transformative energy in compounds of carbon backbones, carrying hydrogen and half as much oxygen. From the time mankind discovered fire, carbohydrates became popular for burning, something which was later extended to their deceased ancestors, already transformed into fossil hydrocarbons. So, the world's most used resource became carbon. As long as only terrestrial carbon was used, the biosphere's metabolism could provide for circularity, but as soon as fossil carbon from earlier eons was consumed, on top of the terrestrial carbon cycle, Western civilization, followed by emerging societies, started to build an increasing atmospheric carbon stock in the form of $\mathrm{CO}_{2}$. Today's widespread do-gooder renewable energy dogmatism unfortunately does not distinguish between retention of primary chemical energy and recovery of secondary energy, which is usually a lavish waste of renewable carbon. Why consume terrestrial carbon by burning or incineration, independent of demand, while nature uses carbon as its favourite form to store chemical energy? For over 200 years, water gas, being a mixture of carbon monoxide and hydrogen, was produced by passing steam over a carbon blaze from e.g. coal. Followed by a water-shift reaction of the water gas, pure hydrogen can be delivered on demand, storing $9.75 \mathrm{MJ}$ clean primary energy per tonne $\mathrm{CO}_{2}$ disposed, after using part of the output as transformation energy input. So, the worst negligence of our civilization is ignoring the crude oil carbon substitute value recoverable from our terrestrial carbonaceous debris. While discarding all this carbon into the air, whether by burning it at extra cost or just letting it rot untreated, potentially poisoning the waters on top, we import three barrels of crude oil per average tonne Municipal Solid Waste [MSW] unnecessarily, that could be substituted by physically captured terrestrial carbon for re-use, either in chemical synthesis or by steam-reforming chemical energy transformations of the energy stored in the recycled carbon for on-demand consummation at arm's length cost, with substituted fossil resources as a renewable energy.

Keywords: $2^{\circ} \mathrm{C}$ carbon budget, acetylene chemistry, carbon capture, carbon efficiency, carbon stock, chemical synthesis, energy storage, hydrogen, re-use, terrestrial carbon.
\end{abstract}

\section{INTRODUCTION}

Today's promoted $\mathrm{CO}_{2}$-neutral combustion of biogenic carbon detrimentally increases the absolute carbon intensity of secondary energy supplied, i.e. compared with the carbon efficiency of natural gas, which in addition can be modulated on demand. In order to comply with the United Nations [UN] Intergovernmental Panel on Climate Control's [IPCC] concept of the world's $2^{\circ} \mathrm{C}$ carbon budget [1], we would need to view carbon as our least abundant resource. Therefore, disposing of it into atmospheric carbon stock by recovering its energy content at poor carbon efficiencies per unit of secondary energy obtained will remain a hoax as long as we dispose of more than our planet's biosphere's $\mathrm{CO}_{2}$ metabolism, no matter where the carbon came from [2].

Decarbonization in climate change mitigation efforts often forgets about mitigating the disposal of unutilized terrestrial carbon into the atmosphere. Organic waste globally represents about $20 \%$ energy-equivalent of the world's primary energy consumption, of which 1/6 today is MSW [3], projected to increase to $1 / 4$ in the next 20 years, becoming 
a $\mathrm{CO}_{2}$ emitter equivalent to transportation in today's technologies, in the order of $>8 \mathrm{Gt} /$ year each [4].

The ratio of electricity from waste or biomass' carbon emissions compared to that from natural gas is 2:1 [5]. But the real carbon efficiency [6] show-stopper of solid carbonaceous fuel driven thermo-chemical plants is intermittency in offtake. Due to the lack of possibilities in modulating the carbon ratio thermo-chemical conversion of solid and heavy fuels into secondary output energy, the ratio may become as bad as 5:1, when compared to natural gas. On the other hand, hydrogen fuel cells can transform the chemical energy into more than twice the electricity than burning the carbon from which the hydrogen could be being produced on demand.

Another lesson should have been learned from biogas installations. Depending on the tank configurations, their adaptability to intermittent demand may be slightly better, but, in view of foreseeable economics in natural gas, there is little chance for competitiveness at arm's length. The most apparent failure of all these concepts is deemed to be the negligence of unused terrestrial carbon value. Taking fossil market prices for that carbon's refurbishment, the price tag is between U\$100-450 per tonne, with natural gas lying right in the middle. Since biogas only valorizes $1 / 3$ of its feedstock's carbon content, it cannot compete. Subsidy schemes introduced to compensate for that turned out to entice the excessive exploitation of carbon-depleting land use, which is also true for most bio-fuels, all just owing to today's misconceptions of $\mathrm{CO}_{2}$-neutral combustion [7].

When looking at the recycling of terrestrial carbon, a typical carbon capture ratio can be seen at $75 \%$ of the feedstock's carbon content, if organic matter is decomposed down to pure carbon and water, nature's two principal energy storage aggregates. Investments in such concepts lie in the order of $75 \%$ of equivalent crude-oil find and development cost. So, less carbon efficient investments may become impaired over their expected lifetime through new terrestrial carbon re-use business models [8].

However, in order to ensure that terrestrial carbon recycling does not result in abusive land use, it is necessary to distinguish between organic debris usefully compostable for agriculture and organic waste streams that should not re-enter the food chain. Because the long-term productivity of soil ligated organic carbon will always outperform any other re-use of terrestrial carbon, whether economically or ecologically, thermo-catalytic carbon recovery should therefore always be seen as the ultimate bridge to close a gap in a circular economy.

\section{METHODOLOGIES}

\subsection{Terrestrial carbon}

Fig. 1 shows the distribution of annually accruing terrestrial carbon, classified in carbon recycling categories of what could be undertaken regarding composting, fermentation and thermochemical decomposition. The total recyclable terrestrial carbon shown in Table 1 only shows the compostable fractions of the total global turnover in the order of 3,863 mega tonnes [Mt] per year [9] that are not useful for agriculture, to guard against accumulations of potential poisons like pesticides, hormones, anti-biotics, etc. in the food chain [10].

Of this, 9\% could satisfy today's worldwide plastic industry's carbon feedstock need [11], which is approximately equivalent to $50 \%$ of global MSW's carbon recovery potential [12]. The remaining 90\% represent about 60 Exa Joule [EJ] stored chemical energy that could theoretically be transformed into renewable hydrogen on demand to complement intermitting renewable energy up to 13.7 PetaWatt-hours electricity $\left[\mathrm{PWh}_{\mathrm{el}}\right]$ fuel cell power generation at 
0.55 tonnes $\mathrm{CO}_{2}$ per $\mathrm{MWh}_{\mathrm{el}}$ footprint from non-fossil carbon. In comparison, this is about twice bio-gas electricity's carbon efficiency or $90 \%$ of that of fossil natural gas power.

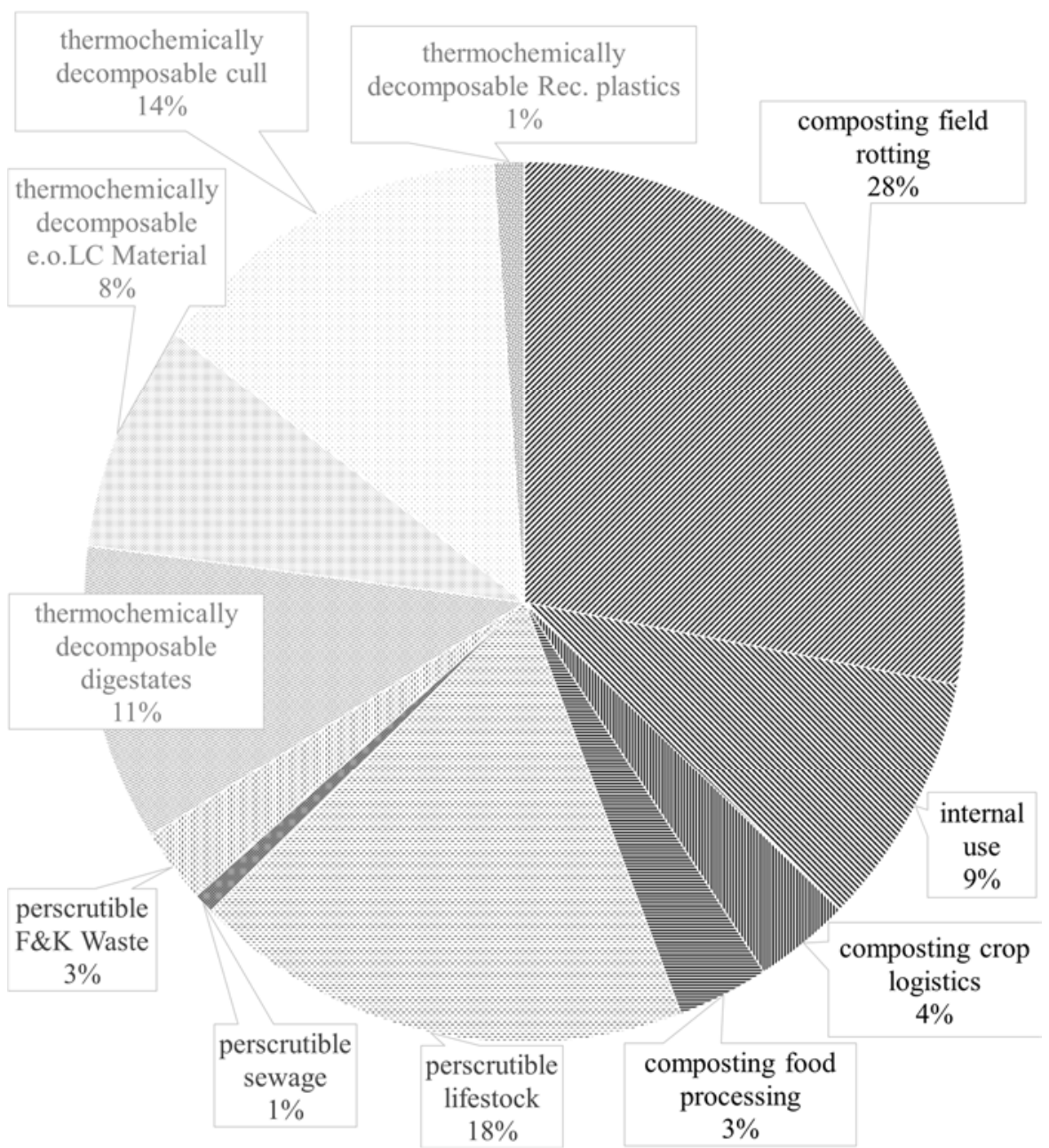

Figure 1: Distribution of annually accruing terrestrial carbon.

Table 1: Manageable terrestrial carbon.

\begin{tabular}{|c|c|c|c|c|}
\hline $\begin{array}{c}\text { Organic } \\
\text { Waste }\end{array}$ & Compostable & $\begin{array}{c}\text { Fermentable } \\
\text { [perscrutible] }\end{array}$ & $\begin{array}{c}\text { Thermo-chemical } \\
\text { [therm. volatilization] }\end{array}$ & TOTAL \\
\hline $\begin{array}{c}\text { Mega } \\
\text { tonnes }\end{array}$ & 4,834 & 8,517 & 5,366 & 18,717 \\
\hline $\begin{array}{c}\text { Recyclable } \\
\text { Carbon }\end{array}$ & 284 & 885 & 1,159 & 2,328 \\
\hline
\end{tabular}




\subsection{Terrestrial carbon complementing renewable electricity}

During 8.5 of 24 hours, wind power usually remains $20-50 \%$ (on average $35 \%$ ) delinquent, therefore $12-15 \%$ additional back-up capacities are needed to satisfy total demand. On the other hand, wind power typically overshoots demand by $20-80 \%$ (on average $45 \%$ ) during 10 of 24 hours, representing $20 \%$ of total demand. Solar Photo Voltaic [PV] might be able to shave $1 / 3$ off peak deficiency on sunny days and could increase daytime excess electricity by maybe $40 \%$ [13].

In $2015,2 / 3^{\text {rd. }}$ of $22.5-\mathrm{PWh}_{\mathrm{el}}$ electricity production stemmed from fossil fuels and $1 / 6^{\text {th }}$ from hydro power [14]. If coal and oil electricity were to be replaced by renewable electricity, solar and wind power would need to be increased 6 -fold to achieve $40 \%$ direct coverage of demand, requiring renewable hydrogen back-up of just $10 \%$ of the above stated potential from recycled terrestrial carbon. This is almost equivalent to the carbon recyclable from $50 \%$ of global municipal wastes.

The spirit of the time currently promotes hydrogen back-up by so-called power-to-gas electrolysis hydrogen from excess renewable electricity production [15]. At first sight, the "if you don't use the abundance, you just lose it" perception entices one to waive any efficiency considerations. However, power-to-gas needs about seven times the auxiliary transformation energy input per hydrogen produced than water-steam reformation of recycled carbon on demand alone does.

In view of the notion that we lose terrestrial carbon into the atmosphere if we do not use it, the question is rather how abundant renewable electricity could be used more effectively than power-to-gas: whether for smart grid concepts or short-term storage in batteries, including electric vehicles or otherwise distributed electrolysis for hydrogen refuelling stations, where a certain structure for storage is already needed [16].

Excess electricity production, however, could be used very cost-effectively for smelting calcium carbide as a precursor to acetylene chemistry. It is not a coincidence that China is currently building the world's largest acetylene chemistry facility adjacent to the Yangtzekiang three-river hydro-station [17]. It has been communicated that the anticipated output capacity would be equivalent to using $25 \%$ of the hydro-power station's nominal capacity rating during excess production beyond grid electricity demand.

Carbon recycling can be set up to deposit carbon capture at the stoichiometric ratio required for carbide smelting onto limestone as catalyst carrier. The carbon monoxide released during smelting can provide about $150 \%$ of energy needed to decarbonize the calcium carbonate by-product of the process. Therefore, acetylene chemistry from recycled carbon, employing excess renewable electricity, could make all downstream acetylene chemistry products renewable materials or chemicals.

\subsection{World in carbon balance by terrestrial carbon reuse}

Globally recycling carbon from all MSW could, together with about $60 \%$ renewable electricity, provide enough storable carbon to cover demand back-up by on demand reforming of hydrogen for fuel cell power generation, as well as all of today's carbon feedstock needed for worldwide polyolefin production, via acetylene chemistry powered by the excess renewable electricity [18]. But the potential for recyclable terrestrial carbon is eight times greater than that represented by MSW today.

Carbon capture steam reformation potential could cover the light duty vehicle [LDV] hydrogen mobility requirement, representing a similar order of magnitude to that of the previously discussed MSW potential. Alternatively, 50\% of that order of magnitude could 
supply the hydrogen used in fertilizer production today. All these options add up to less than $50 \%$ of the total terrestrial carbon recycling potential of carbonaceous residues, which are not useful for agricultural compost.

Using the remaining potential to substitute natural gas in power generation would consume $2 / 3$ of that remaining potential. From an economic and carbon efficiency point of view, it might, however, be more attractive to steam reform natural gas for hydrogen fuel cell power electricity, improving its carbon efficiency by $150 \%$. The recycled terrestrial carbon might be more worthwhile used via a water-gas and partial shift reaction for chemical synthesis gas applications, for example for renewable jet-fuels, etc.

\subsection{Terrestrial carbon}

We define the term terrestrial carbon as any life or deceased matter embodying carbon stock on the planet's surface representing a chemical energy storage. Although waste may contain fossil-derived carbon fractions, bringing it into repeated $\mathrm{CO}_{2}$-skipping life cycles would still make it a terrestrial carbon. Currently, there is much great news about $\mathrm{CO}_{2}$ re-use in chemical synthesis products. Thermodynamically, however, our carbon capture re-use, in the splitting $\mathrm{CO}_{2}$ by a so-called Boudoir-Reaction for example, has been commonly despised in an economic sense [19].

Our world is energy-focused only. It is interesting to see that the mechanisms of subaerial carbon stock movements from matter-ligated carbon into atmospheric carbon stock, namely $\mathrm{CO}_{2}$, have only recently received greater attention. Discarded matter is out of sight and out of mind, but it continues to exist, even when burned up or rotted away into atmospheric carbon stock in the form of $\mathrm{CO}_{2}$. Unfortunately, before that point is reached, a great deal of slowly decomposing waste gets into waters and ends up in oceans. This recently led to rigorous criticism of plastics.

However, even if plastic was completely banned, which would cause food waste to dramatically increase, due to the drastic drop in storage life, the dead hand of our generation remains. Currently, landfills hold 10 times the annual waste arising in anthropogenic resources after use, while, again, five times that amount is stock that remains in use and will eventually also be thrown away [20]. As it is the biggest single resource contained in all these stocks, we should call for "carbon first".

Increasing extreme weather events, as well as predicted sea level risings, represent a potential threat of disposed waste spilling out into waters and ending up as maritime waste. Recent dismay regarding the orders of magnitude and the harm to the ocean habitat, as well as the consequences for the food chain, is unfortunately expressed as moans about symptoms, without exploring the root causes. All this stems from our civilization's disregard for the value that terrestrial carbon would have if it were recycled as a renewable resource.

\section{RESULTS}

\subsection{Accelerated decomposition of MSW into gases [21]}

The difference between total capacity and net in-/output shown in Table 3 is due to a double count of fermentation-residues to be undertaken in a final thermo-chemical treatment. Further, the reduced water content results from a pre-drying step for this fraction. In extension of our previous paper cited below, we herein provide the economic analysis of the corresponding case study [22]. Following nature all starts with an anoxic chemical decomposition of the organic matter. 
Table 2: Based on a Chinese municipality's specification.

\begin{tabular}{|l|l|l|l|l|l|l|l|l|}
\hline tonnes/year & Capacity & water & drying & $\begin{array}{l}\text { CAPEX } \\
1,000 €\end{array}$ & $\begin{array}{l}\mathrm{m}^{3} \\
\mathrm{CH}_{4} / \mathrm{h}\end{array}$ & $\begin{array}{l}\mathrm{m}^{3} \\
\mathrm{H}_{2} / \mathrm{h}\end{array}$ & $\begin{array}{l}\mathrm{m}^{3} \\
\mathrm{CO} / \mathrm{h}\end{array}$ & $\begin{array}{l}\mathrm{m}^{3} \\
\mathrm{CO}_{2} / \mathrm{h}\end{array}$ \\
\hline recyclable & 7,200 & & & 1,080 & & & & \\
\hline compostable & 43,656 & 22,045 & & 2,509 & & & & 7,683 \\
\hline fermentable & 50,414 & 31,445 & & 5,795 & 349 & & & 233 \\
\hline gasification & 47,670 & 13.868 & $-8,264$ & 47,670 & 867 & 3,794 & 1,734 & 2,832 \\
\hline Total & 105,284 & 61,754 & 54,545 & 1,216 & 3,794 & 1,734 & 10,747 \\
\hline
\end{tabular}

Table 3: Valorizing decomposition gas.

\begin{tabular}{|c|c|c|c|c|c|}
\hline tonnes/year & Capacity & Water & $€$ CAPEX & $\mathrm{m}^{3} \mathrm{CH}_{4} / \mathrm{h}$ & $\mathrm{m}^{3} \mathrm{H}_{2} / \mathrm{h}$ \\
\hline Total & 105,284 & & $54,544,728$ & 1,216 & 3,794 \\
\hline $\mathrm{CCU}$ & & & $15,479,406$ & $-4,898$ & 9,578 \\
\hline $\mathrm{CH}_{4}$ Loop & & & $15,350,699$ & 3,682 & $-13,373$ \\
\hline net in-/out & 94,650 & 42,410 & $85,375,333$ & - & - \\
\hline
\end{tabular}

\subsection{Carbon capture for use [23]}

As can be seen in Table 2, we divide the waste stream into compostable, fermentable and thermo-chemical fractions, after separating out any recyclables to optimize CAPEX.

Our dry thermo-catalytic splitting of hydrocarbon gases into neat carbon and hydrogen primarily addresses methane. Since a waste treatment plant rarely has an onsite use for hydrogen, we cannibalize decomposition hydrogen for equilibrium reactions of carbon oxide gas fractions, yielding additional methane for splitting. This loop is applied for as long as available hydrogen is released from the methane splitting, resulting in the two end products: carbon and water - nature's two basic building blocks for new life.

While CAPEX for decomposition into gases is driven by mass input, the decomposition gas valorization follows volume. Due to the high hydrogen yield from gasification, the intermediary methane is approximately quadrupled in the equilibrium loop. Energy-wise, this is an exothermic process, cannibalizing half the hydrogen into reaction water, generating waste heat that may be used elsewhere in the process.

\subsection{Operating cost}

As the recycled carbon is rather to be seen as a refining intermediary, it has to compete against crude oil, which also just represents carbon for $83 \%$ of its mass. We, therefore, show OPEX separately for it. In an acetylene chemistry downstream use, $1 \mathrm{~kg}$ of this carbon can be substituted for 2 litres of crude oil in making plastics. So, the total OPEX, including depreciation as shown in Table 4, would be equivalent to U\$43 per barrel of crude oil, with cash flow breaking even around U\$26 per barrel.

Table 4: OPEX per output product.

\begin{tabular}{|c|c|c|c|c|c|}
\hline OPEX & Gasification & phys. CCU & $\mathrm{CH}_{4}$ Synth. & \multicolumn{2}{c|}{ Total per tonne } \\
\hline in $€$ & \multicolumn{2}{|c|}{ per tonne Carbon processed } & Carbon & Hydrogen \\
\hline direct OPEX & 94.5 & 57.0 & 2.4 & 150.9 & $1,614.7$ \\
\hline fixed OPEX & 39.6 & 39.8 & 52.1 & 131.6 & 78.8 \\
\hline depreciation & 87.5 & 35.4 & 69.5 & 192.4 & 787.5 \\
\hline Total & 218.6 & 132.3 & 124.0 & 474.8 & 2,481 \\
\hline
\end{tabular}


Reforming the recycled carbon yield into hydrogen puts the output product on a par with the upper range of a similar scale European Steam Methane Reforming [SMR] from natural gas [24]. In terms of effectiveness in chemical energy use of carbonaceous residues, this is also the most attractive option.

Returning to our civilization's reckless waste management, the most exciting issue is the OPEX per tonne of MSW treatment! In the case investigated, the carbon content was about $32 \%$ of the input mass. At a $75 \%$ recycling ratio, a tonne of waste can deliver about $240 \mathrm{~kg}$ of carbon, putting OPEX to $€ 114$ per tonne MSW. Revenues may depend on longer-term oil prices and carbon taxes but should actually be able to put carbon recycling into positive cash flow operating regimes.

\section{CONCLUSIONS}

Ignorant and reckless waste management, accompanied by lavish carbon management and the squandering of fossil resources in lieu of terrestrial carbon re-use, seems to have blinded society to nature's core resources: namely, carbon and water, both of which, interestingly, are being over-consumed by our civilization significantly in excess of natural availability.

Originating from special high-tech material developments for highly competitive industries like semiconductors, household appliances or automotive, our team first developed gas-phase carbon deposition for laser-diode synthetic diamond heat-sinks over 20 years ago. Maybe it is from here that our high esteem for this carbon capture technology stems, as diamond is just a very noble form of carbon.

Ten years later, our team had industrialized the concept into a continuous process to produce hydrogen under physical carbon capture for re-use. As it transpired, the most energy-efficient hydrogen release from methane was only recently identified in the course of our studies for its potential application in landfill gas valorization. After five years of feasibility studies, R\&D and validated model simulations with the University of Technology, Vienna, we see this technology as a key to carbon circularity. Of course, nobody dealing with waste would naturally think of such a concept at first hand.

However, people dealing in so-called "clean energy" do not want to deal with carbon at all. In particular, those involved in the hydrogen scene like to ignore terrestrial carbon's adding to the planet's metabolic load. It happens, irrespective of how effectively or not we use it. In the lack of awareness of carbon efficiency, nobody seems to see the substantial resource values being abolished. Carbon recycling aspires to keep as much carbon as possible stored in matter and relies on the effectiveness of hydrogen energy, when it comes to use for energy.

Carbon recycling unlocks local closed-loop economies, creating employment from money saved from fossil carbon imports, often straining currency regimes' trade balances. In Austria, the annual fiscal return on MSW-carbon recycling CAPEX is about $14 \%$, primarily from employment-related taxes, fees and welfare contributions [25]. As per our analysis, effective terrestrial carbon re-use does not incur uncovered cost overruns. Contemporary carbon-neutral energy recovery practices, in comparison, do all need to socialize their lack of competitiveness in the market through complex schemes among consumers: for example, feed-in tariffs, Extended Producer Responsibility [EPR], district heat enforcements at above-market prices, etc.

\section{REFERENCES}

[1] U.N. IPCC Climate Change 2014 Synthesis Report, Nature Geoscience 7, pp. 709$715,2014$. 
[2] Global Footprint Network (WWF); In 2016, Earth Overshoot day fell on August 8; Oakland USA / Geneva CH.

[3] Van Ypersele, J.P., IPCC [BE]; The Climate Change Challenge and the role of bioenergy, World Bioenergy Conference 06/2014, Joenskoping [SE] IPCC Report 2, pp. 112-2012.

[4] World Bank; Global Review of Solid Waste Management, Urban Development Series 2012.

[5] S. Petters; Hybridizing Ambient Carbon Stock Refining with Power to Gas; Poster at $23^{\text {rd }}$ EU-BC\&E; 06/2015.

[6] Guobao Zhang; Specialist Committee for National Energy Commission \& Former Minister of National Energy Administration, New Requirements to Energy Researchers (Opening Remarks), $4^{\text {th }}$ Asian and $1^{\text {st }}$ China IAEE Conference, Beijing, China, Aug. 2014.

[7] Schwarzlmüller, E., Institute of Social Ecology Klagenfurt University, Human Appropriation of Net Primary Production (HANPP), 2007.

[8] Hugo, M.S., EU-Dir. Gen. Environment; Assessments for Commission Proposals (Initiative for Eco-Innovation \& Circular Economy on Waste Management \& Recycling); IconVienna - Apr. 2015.

[9] Aurel, L., Compost Systems; Why it will be impossible to reach the goal of $<2{ }^{\circ} \mathrm{C}$ Global Warming without the integration of Agriculture, COP22 Marrakech, Nov. 2016.

[10] Wirsenius, S., Chalmers University; Global use of agricultural biomass for food and non-food purposes, 2007.

[11] IPCC Report 2015.

[12] Carbotopia S.P., Mitigating Carbon Lavishness by multiple Carbon Re-Use; IAEE Singapore, Jun. 2017.

[13] Electricity Report; Wind Energy in Germany; http://1-stromvergleich.com/stromreport/windenergie/ Accessed Mar. 2017

[14] US Energy Information Administration http://www.eia.gov/tools/faqs/ faq.cfm? $\mathrm{id}=667 \& \mathrm{t}=$ Accessed on: 8 Mar. 2017.

[15] Harasek, M., Vienna University of Technology, Hyly ${ }^{\mathrm{TM}}$ Project for EVN; 2014-2016

[16] Petters, S., www.guobeyond.com; Effective Storage of "negative regime" Renewable Electricity; Blog Jun. 2017.

[17] Mauthner, K. et al., EP 14195574.0; Method and System for Acetylene $\left(\mathrm{C}_{2} \mathrm{H}_{2}\right)$ or Ethylene $\left(\mathrm{C}_{2} \mathrm{H}_{4}\right)$ Production, 2014.

[18] Petters, S., www.guobeyond.com; "Carbon Recycling Enabling Non-Primary Electricity-Recovery by HFCs”, Mar. 2017.

[19] Glinz, H.J., Carbon Capture for Products; Wietersdorfer Group, CO2 Symposium, Linz, Austria, Nov. 2012.

[20] Foerster, K.H., Exec. Dir. Plastics Europe; Identiplast Vienna; Feb. 2017.

[21] Hofbauer, H., Vienna University Technology; "Future Energy Technology” Brochure, 2011.

[22] Petters, S., guo - Business Development Consult; "Waste-Valorization by Municipal Solid Waste Carbon Use in a Chinese Township"; WESSEX Medellin; 2015.

[23] Mauthner, K., BMVIT Report 1/2011, Factory of the Future, EU-FP5.

[24] Lichtscheidl, J., Sen. Advisor OMV; personal discussions; Vienna Jan. 2017.

[25] Helmenstein, C., Economica Institute for Economic Studies, Bio-refineries for Wastes "Regional- and macro-economic impact, fiscal performance and foreign affairs contribution" (for guo Business Development), 2013. 